\title{
No One Rides for Free!: Three Styles of Collaborative Consumption
}

Hugo Guyader

The self-archived postprint version of this journal article is available at Linköping University Institutional Repository (DiVA):

http:/ / urn.kb.se/ resolve?urn=urn:nbn:se:liu:diva-149072

N.B.: When citing this work, cite the original publication.

Guyader, H., (2018), No One Rides for Free!: Three Styles of Collaborative Consumption, J ournal of Services Marketing. https:// doi.org/ 10.1108/J SM-11-2016-0402

Original publication available at:

https:/ / doi.org/ 10.1108/J SM-11-2016-0402

Copyright: Emerald

http:// www.emeraldinsight.com/ 


\title{
No One Rides for Free! \\ Three Styles of Collaborative Consumption
}

\author{
Hugo Guyader*
}

\begin{abstract}
Purpose - This paper focuses on collaborative consumption; that is, the peer-to-peer (P2P) exchange of goods and services facilitated by online platforms. Anchored in the access paradigm, collaborative consumption (e.g., accommodation rental, ridesharing services) differs from commercial services offered by firms (e.g., B2C carsharing). The aim of this study is to examine the nuanced styles of collaborative consumption in relation to market-mediated access practices and socially mediated sharing practices.

Design/methodology/approach - Following the general research trend on mobility services, the context of long-distance ridesharing is chosen. Data collection was conducted using participant observation as peer service provider, 11 ethnographic interviews of consumers, and a netnographic study of digital artefacts.

Findings - Using practice theory, 10 ridesharing activities were identified. These activities and the nuances in the procedures, understandings, and engagements in the ridesharing practice led to the distinction of three styles of collaborative consumption: (1) Communal collaborative consumption, which is when participants seek pro-social relationships in belonging to a community; (2) Consumerist collaborative consumption, performed by participants who seek status and convenience in the access lifestyle; and (3) Opportunistic collaborative consumption, when participants seek to achieve monetary gain or personal benefits from abusive activities.

Originality/value - By taking a phenomenological approach on collaborative consumption, this study adds to the understanding of the sharing economy as embedded in both a utilitarian/commercial economic system, and a non-market/communal social system. The three styles of collaborative consumption propose a framework for future studies differentiating P2P exchanges from other practices (i.e., B2C access-based services, sharing).
\end{abstract}

\section{Keywords}

Access-based consumption; Collaborative consumption; Practice theory; Sharing economy; Ridesharing

\footnotetext{
* Department of Management and Engineering, Linköping University, SE-58183 Linköping, Sweden. Email: hugo.guyader@liu.se
} 


\section{Introduction}

The 'sharing economy' phenomenon exhibits diverse practices departing from traditional consumption. First, there has been a rise of anti-consumption practices such as swapping, redistribution, or foodsharing driven by strong community ideals and generalized reciprocity (e.g., Albinson and Perera, 2012; Gollnhofer et al., 2016; Martin et al., 2015). Second, within the paradigm shift from ownership to access-based consumption, service firms (e.g., Zipcar) offer the temporary utilization of commercial goods to customers mostly driven by utilitarianism and selfinterest (Bardhi and Eckhardt, 2012; Hazée et al., 2017; Lamberton and Rose, 2012; Schaefers et al., 2016b). Third, collaborative consumption is facilitated by online platforms (e.g., BlaBlaCar, Airbnb) that enable the peer-to-peer (P2P) exchange of privately owned underutilized assets (e.g., seats, accommodation) with no employees involved (e.g., Benoit et al., 2017; Hamari et al., 2016; Zervas et al., 2017). Most empirical research on the sharing economy is concerned with the traditional B2C facets of the phenomena, whereas this paper focuses on the P2P collaborative consumption practices that deserve more academic attention (Kumar et al., 2018; Oyedele and Simpson, 2018; Perren and Kozinets, 2018).

Belk (2014b, p. 1595) emphasized that "sharing is a phenomenon as old as humankind, while collaborative consumption and the 'sharing economy' are phenomena born of the Internet age." Critics argue that private resources were already shared in close social circles (e.g., ridesharing among friends, hitchhiking) before online platforms incorporating social relations into matchmaking business models and misusing the words sharing and community (Belk, 2014a, 2017; Scholz and Schneider, 2016). As such, several studies have described ideological tensions across sharing economy practices, between market-mediated exchange norms with aspects of profitmaximization, self-interest, and utilitarianism; and non-market social norms with elements of solidarity, mutuality, generalized reciprocity, and communal belonging (Albinsson and Perera, 2012; Eckhardt and Bardhi, 2016; Habibi et al., 2016; Herbert and Collin-Lachaud, 2017; Martin et al., 2015; Perren and Kozinets, 2018; Scaraboto, 2015; Schor et al., 2016). For instance, BlaBlaCar rebranded its ridesharing platform with a more mature visual identity emphasizing the personal connections (e.g., conversations), high levels of trust (almost as much as close social circles), and enriching exchanges between its community members, while hoping to justify its criticized commission (considered increasingly expensive for a "super low-cost travel network") with evermore convenient and efficient search functions (Butt D'Espous et al., 2018). That is, collaborative consumption practices are not true sharing practices because they are market-mediated, but they are embedded with meaningful social interactions. In line with practice theory and market studies (e.g., Araujo et al. 2010; Geiger et al., 2014), the performance of collaborative consumption is dependent on the platform provider's internal performance (e.g., website usability, technical functionalities), but also and much more on the peers' interactions, which are external resources outside of the platform provider's direct control (Benoit et al., 2017; Kumar et al., 2018). However, there is a lack of research on how these participants in collaborative consumption integrate various facets of the conflicting market exchange and pro-social norms into their own practices and interactions with each other.

Service research would particularly benefit from further investigating collaborative consumption practices (Benoit et al., 2017; Hofmann et al., 2017; Oyedele and Simpson, 2018; Yang et al., 2017) where P2P service exchanges are less institutionalized (that is, participants are equal members of a network or community) in contrast to the traditional B2C context of access- 
based services (e.g., Schaefers et al., 2016b) with no interpersonal exchanges (i.e., self-service). This causes variation in the collaborative consumption practices according to participants' procedures, understandings, and engagements (Schau et al., 2009). Moreover, cultural or social class differences such as a collectivistic orientation (Belk, 2010; Belk and Llamas, 2012; Davidson et al., 2018) or a lower socioeconomic status (Eckhardt and Bardhi, 2016) influence sharing economy practices. Similarly, these practices reveal different degrees of true sharing and market exchange orientations (Habibi et al., 2016). In particular, different practices (e.g., BlaBlaCar, Airbnb) are unified by a unique collaborative consumption style (Herbert and Collin-Lachaud, 2017).

This study explores what peer providers and consumers do when performing a collaborative consumption practice, and to what extent the differences in procedures, understandings, and engagements lead to different styles of collaborative consumption. In the context of long-distance ridesharing, the research is based on qualitative data: $2,250 \mathrm{~km}$ of participant observation as peer service provider (i.e., driver), 11 ethnographic interviews of consumers (i.e., passengers), and a netnographic study of digital artefacts accessible online between 2009 and 2016. The analysis revealed 10 activities performed by ridesharing participants and identified three collaborative consumption styles: Communal (pro-social), consumerist (commercial), and opportunistic (exploitative).

This paper's main contribution lies in conceptualizing these styles of collaborative consumption. That is, there is not one unique way to participate in $\mathrm{P} 2 \mathrm{P}$ exchanges, but three that coexist. Such nuances in collaborative consumption relate to purely pro-social sharing (Belk, 2010), and other market-mediated access-based practices (e.g., Schaefers et al., 2016b). That is, the communal style of collaborative consumption is the closest to true sharing practices (but it is market-mediated), the consumerist style is the closest to B2C access-based services (but services are exchanged $\mathrm{P} 2 \mathrm{P}$ ), and the opportunistic style is a symptom of the increasing commercial orientation and the widespread adoption of collaborative consumption practices (which had not been previously identified in the literature). The three styles propose a relevant framework for future service research on collaborative consumption.

\section{Practice Theory}

Practice theory derives from sociology (e.g., De Certeau, 1984; Reckwitz, 2002; Schatzki, 1996), has been introduced to consumer research (e.g., Shove and Pantzar, 2005; Warde, 2005), and is commonly used in market studies (e.g., Araujo et al., 2010). This study follows Warde (2005, p. 150), who sought to understand practices rather than consumption. Through practices, consumers (or peers) are not conceptualized as passive actors, but as active producers of a culture. As community members or market actors, they reappropriate rituals, symbols, language, and other 'arts of doing' by participating in each other's practices and, in doing so, influence one another (De Certeau, 1984; Geiger et al., 2014; Schau et al., 2009).

Practices are the coordination of diverse tangible, social, cultural elements, which are reproduced and changed through concrete performances. A practice is defined as "[...] a temporally unfolding and spatially dispersed nexus of doings and sayings" (Schatzki, 1996, p. 89). Activities constituting practices can be identified as "performing" or "doing" (cognitive and behavioral), ranging in levels of complexity and interactions with others (McColl-Kennedy et al., 2012, p. 6). 
This set of activities enacted by practitioners in various manners revolves around a combination of various interconnected elements: Practical understandings, rules and instructions, emotional goals and states, motivations and competences, and material goods (Reckwitz, 2002; Schatzki, 1996; Schau et al., 2009; Shove and Pantzar, 2005; Warde, 2005).

Specific practices can be further personalized, nuanced, or stylized. A practice style is defined as "a specific styling of a practice that orders and roots the service system in a particular value creation effort" (Chandler and Chen, 2016, p. 823). The same activities can be performed in different practice styles, but with a varying degree of interactions (McColl-Kennedy et al., 2012), motivation, and enactment (Chandler and Chen, 2016). For instance, McColl-Kennedy et al. (2012) identified five practice styles ("team management", "insular controlling", "partnering", "pragmatic adapting", and "passive compliance"), while Chandler and Chen (2016) found four practice styles ("individual-extant", "social-extant", “individual-modified", and "social-modified") in the commercial service contexts of crafts, healthcare, and fitness.

Previous studies have used practice theory to investigate the sharing economy (Hazée et al., 2017; Herbert and Collin-Lachaud, 2017; Huber, 2017; Schor et al., 2016). Practice theory is valuable because it enables considering that the role of platforms as service providers is to facilitate interactions and that individuals' practices influence each other, which both consequently influence the framing and narrative of the diverse practices in the sharing economy. For instance, Uber has sought to redesign existing institutions, thereby shifting agency and mandates to individual market actors (Giesler et al., 2015), and Airbnb continuously attempts to "re-frame its practices" to appease political opposition, and incorporate notions of community and sustainability (Stabrowski, 2017). Using practice theory as a framework, collaborative consumption practices themselves (what participants do, how they do it, and what this does) become the focus of analysis. This conceptualization is in line with market studies (e.g., Araujo et al., 2010): The practices performed in P2P markets are influenced by both the participants in collaborative consumption, and the service providers owning and operating online platforms. Supporting Chandler and Chen's (2016) conceptualization of practice styles, Herbert and Collin-Lachaud (2017) argued that various collaborative consumption practices (e.g., ridesharing, accommodation rental) are united by a practice style that differs between the dimensions of commercial/alternative market mindsets, and high/low degrees of socialization. That is, collaborative consumption practices can be performed in various styles according to the participants' engagements, understandings and procedures.

\section{Sharing economy practices}

The sharing economy has fundamentally reworked existing consumption practices toward new socio-material assemblages and relationships (Stabrowski, 2017; Zervas et al., 2017). Table 1 and the following digests the most relevant concepts and practices related to the sharing economy with representative references: (A) True sharing practices (i.e., socially mediated, community-oriented), (B) access practices (B2C market-mediated exchanges, dominated by utilitarian motives), and (C) collaborative consumption practices (P2P market-mediated exchanges, social norms are emphasized). 


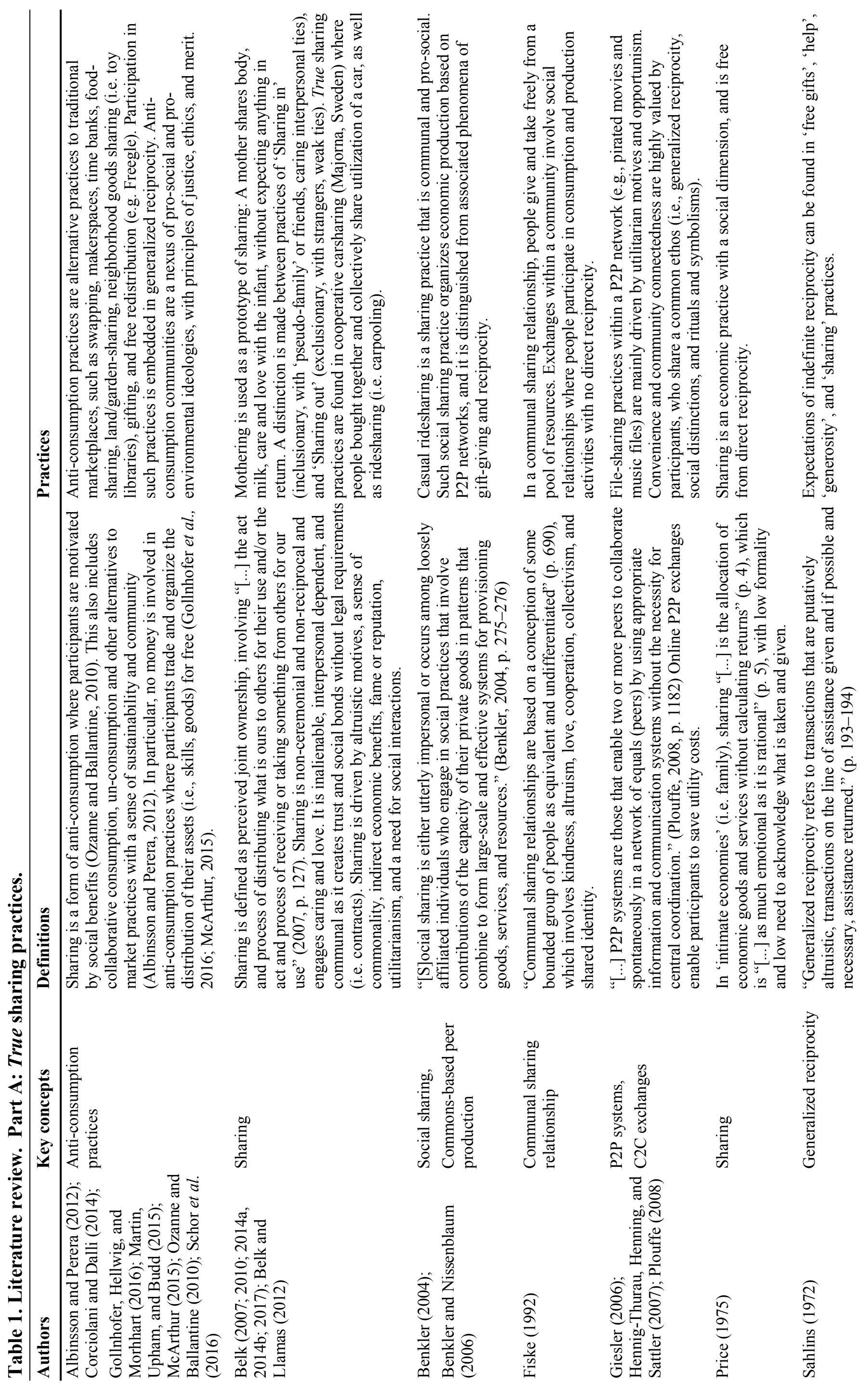




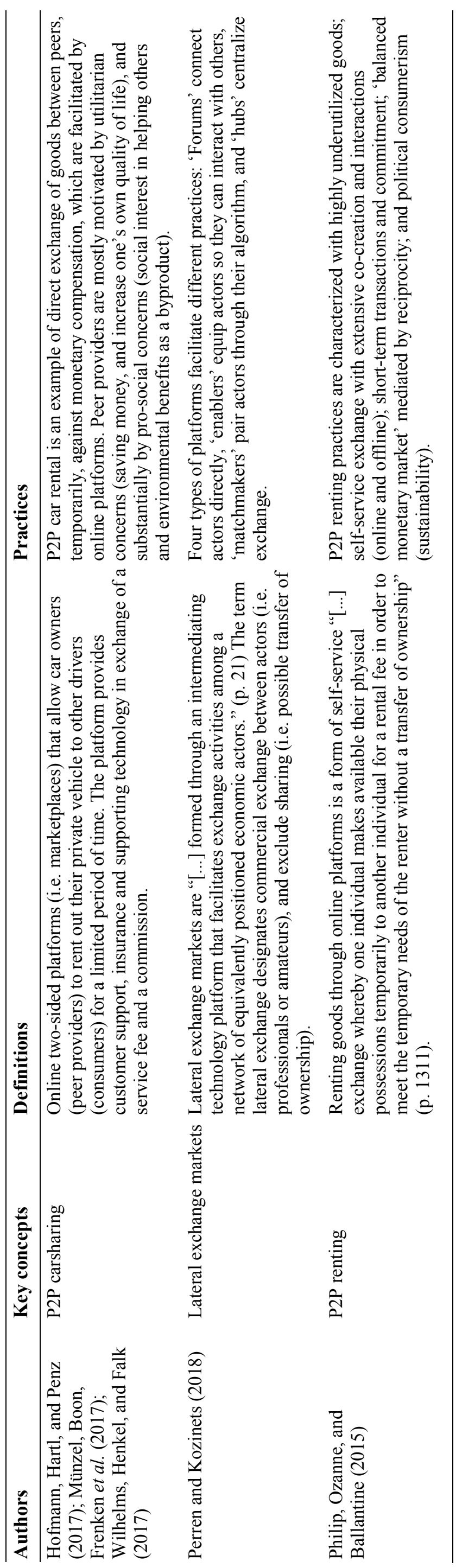




\section{True sharing practices}

Belk argued that the 'pseudo-sharing' practices (that is, access-based or collaborative consumption) of the sharing economy are not true sharing, because of "[...] the presence of profit motives, the absence of feelings of community, and expectations of reciprocity" (Belk, 2014a, p. 7). In contrast, sharing is defined as "[...] voluntary lending, pooling and allocation of resources, and authorised use of public property, but not contractual renting, leasing, or unauthorised use of property by theft or trespass" (Belk, 2007, p. 127). Moreover, sharing is not market-mediated, non-compensated, and does not involve transfer of ownership (Belk, 2010). The pure prototypes of sharing practices are mothering, and the pooling and allocation of resources within a family (Belk, 2007, 2010). This is in line with the anthropology literature: Sharing practices are associated with generalized reciprocity, and defined as an economic behavior with a heavily weighted social dimension (Price, 1975; Sahlins, 1972). Ridesharing practices among family and friends are also used to illustrate "online-facilitated offline sharing" (Belk, 2014a, p. 15) or "Internet-facilitated sharing" (2014b, p. 1596), as well as commons-based peer production (Benkler and Nissenbaum, 2006). Benkler (2004) also argued that "sharing nicely" is a pro-social practice, but one that relies on the economic system to collaborate and produce wealth within communities. This kind of social relationship has been labelled "communal sharing" because it involves kindness, altruism, love, cooperation, collectivism, and shared identity (Fiske, 1992).

Further, a distinction is made between true "sharing in" (inclusionary, with family and friends, caring interpersonal ties, sense of community), and "sharing out" (exclusionary, with strangers, weak ties, limited sense of community or caring), which is closer to the norms of economic exchange found in the sharing economy (Belk, 2010, 2014a, 2017). A range of practices are performed as alternatives to commercial consumption, that is, without the exchange of money, which are embedded with such values of sharing in, generalized reciprocity, and communal belonging. Anti-consumption practices include neighbors sharing goods within their local community, such as toy libraries (Ozanne and Ballantine, 2010), or grassroots carsharing (Belk, 2014a), or strangers recirculating books via online communities (Corciolani and Dalli, 2014). Digital file-sharing practices, such as the P2P network Napster, are embedded in community connectedness, but also financial cost savings (Giesler, 2006; Hennig-Thurau et al., 2007; Plouffe, 2008). Participants can also trade and organize the redistribution of goods through alternative marketplaces (i.e., offline), such as Freecycle, Freegle, or Really Really Free Markets (Albinsson and Perera, 2012; Martin et al., 2015). Others swap or redistribute food (Gollnhofer et al., 2016; Schor et al., 2016), or they organize the production of food through LandShare (McArthur, 2015). Participants in such non-compensated practices are mostly motivated by the social benefits of communal belonging, a pro-environmental ideology, and principles of justice (Albinsson and Perera, 2012; Gollnhofer et al., 2016; McArthur, 2015; Ozanne and Ballantine, 2010). Eventually, one's cultural background can influence sharing practices, such as the rituals of hospitality among family and friends in Asian and Western cultures (Belk, 2010), or the more relaxed norms (i.e., less individualistic and materialistic) in Spain than in North America (Belk and Llamas, 2012).

\section{B2C access practices}

Lovelock and Gummesson (2004) argued for an access paradigm in which rental, outsourcing, or leasing services offer the benefits of ownership, but without ownership. In this paradigm, firms providing access to their assets rather than acquisition-based models offer such access-based 
consumption to customers, that is, market-mediated exchanges with no transfer of ownership (Bardhi and Eckhardt, 2012, 2017). Access-based services (Hazée et al., 2017; Lawson et al., 2016; Schaefers et al., 2016a, 2016b), product-sharing services (Johnson et al., 1998), nonownership services (Habibi et al., 2016; Moeller and Wittkowski, 2010; Wittkowski et al., 2013) and other product-service systems (Catulli et al., 2013) offer temporal solutions in which multiple customers can use the same tangible good sequentially (rather than simultaneously, as in collaborative consumption). The term "commercial sharing" is also used in relation to firms that retain ownership of the goods that are offered through rentals (Akbar et al., 2016; Lamberton and Rose, 2012; Milanova and Maas, 2017).

Hazée et al. (2017) argued that customers of access-based services participate to alleviate the burdens of ownership (see Moeller and Wittkowski, 2010), but they also encounter the 'burdens of access' that are the consumption barriers (e.g., difficulty of understanding or trusting technology, fear of contamination from other customers), as well as five practices performed to attenuate those barriers (i.e., distancing, elaborating, managing, controlling, and relating). In the case of Autolib carsharing, customers also engage in appropriation practices: Controlling (e.g., driving), knowing (enabled by the uniformity of the vehicles' design creating habits, and personalization), and creating (as they invest time and energy).

Studies on carsharing (i.e., Zipcar, Car2Go) illustrated how access-based consumption is largely driven by self-interest and utilitarian motives rather than altruistic concerns, and customers distrust their fellow customers, avoid identification with them, and behave opportunistically against others, the goods accessed, and the firm (Bardhi and Eckhardt, 2012; Gruen, 2016; Lamberton and Rose, 2012; Schaefers et al., 2016a). Such access practices resemble a consumerist ideology (in contrast with sharing practices) because these services are only temporary for some customers until they can afford car ownership (Bardhi and Eckhardt, 2012; Herbert and Collin-Lachaud, 2017; Lawson et al., 2016). Similarly, customer misbehavior practices (e.g., trashing the car) in accessbased services is contagious, but communal identification actually reverses this effect (Schaefers et al., 2016b).

\section{Collaborative consumption practices}

When peer providers and consumers exchange privately owned goods and services through online platforms, it is a collaborative consumption practice (Benoit et al., 2017; de Rivera et al., 2017; Hamari et al., 2016; Herbert and Collin-Lachaud, 2017; Huber, 2017; Möhlmann, 2015; Parguel et al., 2017). Belk (2014b, p. 1597) explained that "collaborative consumption is the subset of Bardhi and Eckhardt's (2012) notion of access-based consumption" as participants access assets at the same time, not successively, so it is also called "consumer-to-consumer provision of access-based services" (Wilhelms et al., 2017, p. 39). As "a platform provider links a consumer that aims to temporarily utilize assets with a peer service provider who grants access to these assets and with this delivers the core service" (Benoit et al., 2017, p. 220), the definitive criteria of collaborative consumption with two or more participants, privately owned goods, no ownership transfer (temporality of access), and market mediation, make it conceptually different from access-based services where goods are owned by $\mathrm{B} 2 \mathrm{C}$ firms, as well as from true sharing, which is socially mediated. 
Hofmann et al. (2017) defined collaborative consumption as consumer networks sharing resources, in a confidence climate (i.e., in contrast with the service climate of B2C interactions). They further distinguish between platform-regulated communities (e.g., GetAround, P2P car rental), and self-regulating communities (e.g., Majorna, cooperative carsharing; see Belk, 2014a). Most collaborative consumption practices are made easier by online platforms such as Airbnb facilitating accommodation rental (Bucher et al., 2016; Habibi et al., 2016; Huber, 2017; Zervas et al., 2017), or LeBonCoin facilitating goods rental and second-hand sales (Herbert and Collin-Lachaud, 2017; Parguel et al., 2017; Philip et al., 2015). The main activities of a dual-sided platform relate to optimizing the exchange organization between peers and their competitive objectives (i.e., two distinct but interdependent value propositions are formulated), designing a governance system, while creating trust and reducing the perceived risk of P2P exchanges (Benoit et al., 2017; de Rivera et al., 2017; Einav et al., 2016; Kumar et al., 2018; Muzellec et al., 2015; Perren and Kozinets, 2018; Rochet and Tirole, 2006). Herbert and Collin-Lachaud (2017) also found that collaborative consumption is a repertoire of practices unified by a unique practice style dominated by activities linked to commercial exchange, but that these transactions are also associated with the alternative ideas of community, gift-giving, solidarity, and generosity.

In the context of shared mobility, P2P car rental is a popular collaborative consumption practice: Platform providers (e.g., Drivy, GetAround) have developed online marketplaces that allow car owners (peer service providers) to rent out their private vehicle to other drivers (consumers) for a limited period of time (Hofmann et al., 2017; Münzel et al., 2017; Wilhelms et al., 2017). Ridesharing (e.g., via BlaBlaCar, or Kangaride) has also been used to illustrate collaborative consumption (Benoit et al., 2017; Davidson et al., 2018; Herbert and Collin-Lachaud, 2017). Overall, several studies show that participation in collaborative consumption is driven by social motives: Participants want to make new friends, socially interact, and feel that they belong to a community (Hamari et al., 2016; Herbert and Collin-Lachaud, 2017; Möhlmann, 2015; Wilhelms et al., 2017).

This review of sharing economy practices discerned that the prototype of true sharing does not apply to market-mediated exchanges. As such, sharing practices differ from the commercial orientation found in the access-based and collaborative consumption practices. However, the values of sharing, generalized reciprocity, and communal belonging are found in alternative consumption practices that can be facilitated by online platforms, and where community members share resources for free. In contrast to sharing practices, access-based services provided by firms offering convenience and novel relations to ownership of goods to customers (e.g., self-service technology, on-demand service delivery) are forms of B2C exchanges (not P2P), dominated by economic and utilitarian motives, and characterized by both direct and negative reciprocity. Eventually, the collaborative consumption practices facilitated by online platforms are also embedded in the access paradigm (i.e., shifting away from ownership-based consumption), but they are different from access-based services provided by firms, in that the services are provided by peers with their own assets. However, we know that P2P markets are impregnated with ideological tensions between communal and commercial orientation. As such, a deeper understanding is required about what peer service providers and consumers do when they engage in collaborative consumption practices. 


\section{Method}

Rudmin (2016) called for consumer researchers to observe what previous studies have overlooked in their descriptions of the various practices in the sharing economy. This study employed a qualitative research design that facilitates the exploration of responses in context and the obtention of in-depth information on new phenomena (Dubois and Gadde, 2002). Data were collected using a netnographic study, participant observation, and ethnographic interviews - phenomenological techniques that facilitate a better understanding of the lived experience of the informants (Van Maanen, 2011).

The collaborative consumption practice chosen for this study is ridesharing (i.e., carpooling). Ridesharing has been defined as "adding additional passengers to a pre-existing trip. Such an arrangement provides additional transportation options for passengers while allowing drivers to fill otherwise empty seats in their vehicles" (SUMC, 2015). Celebrating 10 years in 2016, BlaBlaCar is the world's largest online platform for the organization of ridesharing. Such P2P exchanges do not include chauffeured-vehicle services (transportation network companies) as ridesharing participants contribute monetarily only to share travel expenses, not to remunerate the driver. In 2012, BlaBlaCar deployed an online registration system to replace the exchange of cash, guarantee payments, and include a cancellation policy. This business model charges passengers an 11.88 percent commission and a $€ 0.99$ fixed fee per reservation. Preceding the reservation, passengers and drivers can communicate via the platform on the ride description and exchange direct online messages, but personal contact information is hidden. Passengers pay upon reservation and receive a code by SMS, which they communicate to the driver in the car so that the payment is transferred upon completion of the ride. ${ }^{1}$

\section{Netnography}

Previous research on the sharing economy employed netnography, as activities are facilitated digitally and platforms gather communities of members interacting online (Corciolani and Dalli, 2014; Gollnhofer et al., 2016; Martin et al., 2015; McArthur, 2015; Perren and Kozinets, 2018; Scaraboto, 2015). Netnography is a research method situated between the vast searchlights of big data analysis and the close readings of discourse analysis (Kozinets, 2015), used here to provide insights on the ridesharing culture, experiences, and interactions between participants (e.g., communal exchanges, online rules, practices, innovative forms of collaboration and organization, and manifestations of creativity). From January 2015 to June 2016, the netnographic approach was used following the 12 phases described by Kozinets (2015). The data included 25 online conversations with ridesharing participants, 22 BlaBlaCar presentations and its FAQ pages, 349 testimonials and 59 portraits of BlaBlaCar members, 81 opinion articles and independent blogposts, as well as associated comments, forum messages, videos, and other artefacts published and accessible online between December 2009 and June 2016 (see Appendix A). These artefacts constitute approximately 900 pages of text. The netnography predominantly reveals how the ridesharing practice has evolved since BlaBlaCar's early days, and particularly during 2011-2013 with the change of business model (i.e., from free to fee), as well as during the funding rounds in

2014-2015 (international expansion), both from the perspectives of the online platform service providers and ridesharing participants. 


\section{Participant observation and ethnographic interviews}

The netnography revealed that there were data available to capture the drivers' point of view on ridesharing, but a lack of insights on the passengers' experience. While most blogposts and online articles mention the same basic motivations for sharing rides as a passenger (i.e., cost-saving compared with the train or car ownership), the literature reviewed in the previous section presents evidence of additional consumer attitudes and motives influencing participation in collaborative consumption (e.g., altruism, eco-consciousness, social connectedness). According to BlaBlaCar, 30 percent of their platform members take on the role of driver and 70 percent passenger (not taking into consideration participants who switch roles). Therefore, as the netnography provided confirmatory findings about the drivers, the other parts of the study focused on the passengers.

The author signed up on BlaBlaCar in 2012 and shared 19 rides both as a passenger and driver prior to the study. Therefore, the member profile was fully completed and displayed positive peer ratings. This past experience, supplemented with the ongoing netnographic study, provided a valid background impregnated in ridesharing culture, its associated vocabulary, and accustomed with the context and norms of online and offline interactions. This preliminary understanding enabled the author to focus the participant observations and to be more specific in the discussion topics, while developing an insightful rapport with passengers (Spradley, 1979). Five rides were posted on BlaBlaCar during May 2015 (see Appendix B). Interactions occurred with 35 potential passengers who inquired about various aspects of the rides, and 12 reserved a seat. Two of them reserved for an additional passenger, two cancelled, and one did not show up (i.e., 11 ridesharing participants). Prior, during and after this ridesharing experience of $2250 \mathrm{~km}$, field notes were taken. These notes were initially inscriptive (i.e. in the field) and condensed, such as mental notes while observing, 'scratch notes' during coffee breaks or speech-text recordings while waiting for passengers, but they were also descriptive (i.e. full field notes) and expanded, such as summaries of conversations, situations, and reflections after the rides (Emerson et al., 2011; LeCompte and Schensul, 2012; Spradley, 1979).

The ethnographic interviews were viewed as "[...] a series of friendly conversations into which the researcher slowly introduces new elements to assist informants to respond as informants" (Spradley, 1979, p. 58). During the 31 hours in the car, the driver's identity as a researcher was always revealed to the passengers. The purpose of the study was clarified if necessary. As the netnography influenced the participant observation and ethnographic interviews, the discussions in the car were directed toward their perspective of consumer of a mobility service provided by peer providers. In other words, the researcher acted as an expert on the questions, but absolutely not on the content of the answers. The questions and follow-up probes were mostly descriptive, regarding the coordination of itineraries before the rides, their perception of the professionalization of ridesharing, the trust system and the influence of peer ratings, their expectations regarding interactions with other participants, the importance of the ridesharing community and culture, their best/worst ridesharing experience, their understanding of the reservation (and cancellation) systems, their participation motives, and more, depending on the conversations.

Table 2 contains information gathered from the 14 passengers' online profile and from interactions, both online and in the car. The 11 interviewees (excluding cancelled rides) were between 19 and 30 years-old and represented six different nationalities. Four passengers were seasoned ridesharing participants (including as drivers), five had a minor experience (including with 
other ridesharing platforms), and two were newcomers to ridesharing. The average distance was $277 \mathrm{~km}$ per passenger.

\section{Analysis}

A data-driven content analysis allowing room for discovery (Dubois and Gadde, 2002) was realized. The netnographic artefacts, interview data, online interactions, and field notes were reviewed iteratively and categorized with open codes (Emerson et al., 2011; Ritchie and Spencer, 2002): Whether ridesharing participants or platform providers' perspectives, as well as between peer providers and consumers; between positive (praise) and negative (critique) attitude towards BlaBlaCar's platform; levels of economic, social, or environmental participation motives; activities performed; and market or social relationship norms. Following the stages of framework analysis (familiarization, identifying a thematic framework, indexing, charting, mapping, and interpretation), fragments of field notes and interview summaries were placed into categories with themes that represented similar features, reducing the dataset through summaries and synthesis while retaining links to the original data (Ritchie and Spencer, 2002). First, the ridesharing practice was broken down according to Schau et al.'s (2009) analogy: (1) Procedures, or "explicit know-that," rules, principles, precepts, and instructions; (2) understandings, or "tacit know-how" about what to say and do; and (3) engagements, commitments, or emotionally charged ends and purposes. This analogy was used by service researchers to identify value co-creation practices (e.g., Echeverri and Skalen, 2011). Second, the empirically sensitized concepts and open codes (Emerson et al., 2011) generated 10 main ridesharing activities repeatedly identified in the dataset. Third, the nuances and specific styling of the activities performed by participants (Chandler and Chen, 2016; McCollKennedy et al., 2012) are identified as emerging themes throughout the dataset as three styles of collaborative consumption.

\section{Findings}

\section{The ridesharing practice}

The ridesharing practice between co-workers or neighbors dating back from the 1970s was elaborated and facilitated by the recent technological advances increasing trust between strangers. Nowadays, BlaBlaCar members trust each other almost as much as friends and family members. However, the platform owners were criticized for "killing the original ridesharing philosophy" when adopting the current business model in 2012. Many community members describe feeling cheated by, and "at war" with BlaBlaCar for making an ad hoc practice more commercial and less altruistic. To articulate a deeper understanding of ridesharing, the practice is further analyzed according to Schau et al.'s (2009) analogy: Procedures, understandings, and engagements. 


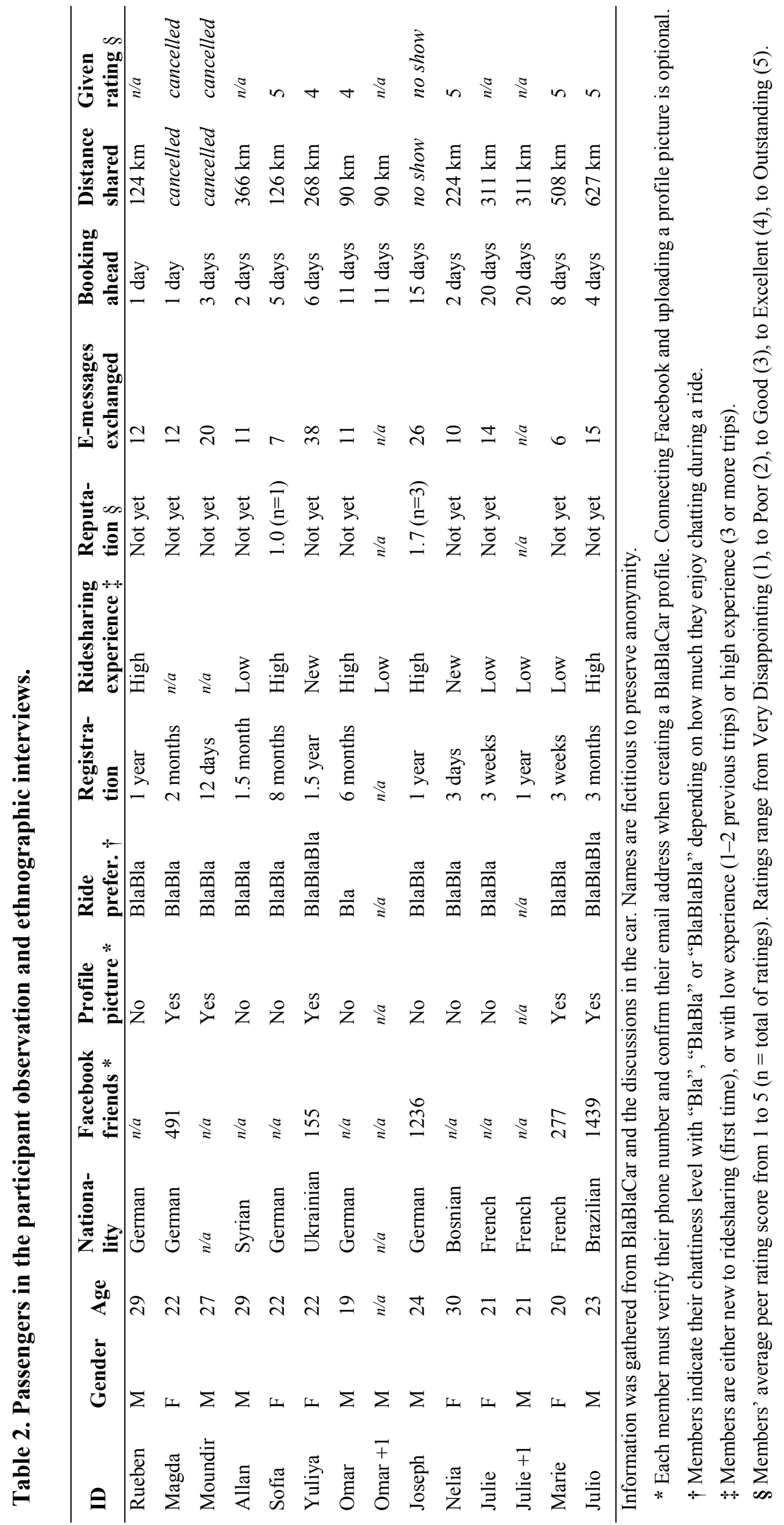


First, the procedures of ridesharing have evolved over time. BlaBlaCar has institutionalized the practice with formal procedures through its platform functionalities (e.g., minimum requirements to create a profile), but also informal procedures through its communication (e.g., selected community members' guest blogposts), code of conduct, and FAQ pages. To participate in ridesharing via BlaBlaCar's platform, one follows the practical steps of creating and completing a member profile, providing personal information, coordinating meeting times and locations prior to the ride, exchanging journey details, being courteous and respectful toward others, providing the agreed-upon monetary compensation or exchanging the code in the car, and reviewing the experience through peer ratings. Moreover, the peer provider (i.e., car owner) is formally expected to respect additional rules related to driving and ownership (e.g., insure the car, possess a driver's license, obey the traffic code). Ridesharing participants adopt the procedures that render the practice feasible: The more procedural the performance, the more efficient the ridesharing.

Second, the understandings, or implicit know-hows of ridesharing as a practice by its participants are largely influenced by the platform. Historically, ridesharing, as a form of digitalized hitchhiking, was first an alternative to market consumption (e.g., instead of owning a car, or paying public transportation), which became mainstream and (re)shaped as a P2P market for drivers and passengers to trade externalities. That is, ridesharing means being able to reduce the environmental impact of driving alone, establish social relationships, and share travel costs. These understandings are achieved at varying degrees among participants depending on their accumulated experience and knowledge of the original ridesharing culture.

Third, the emotional engagements in ridesharing vary from an attachment to sharing and the original ridesharing ethos as a pro-socioenvironmental movement, to a more commercial and professional orientation. That is, what motivates and what is desirable in the ridesharing practice evolved over time, mainly from an engagement in sustainability (i.e., increasing car utilization), to an engagement in economic efficiency (i.e., increase cost savings). As such, ridesharing participants can be stimulated by the social connections, the eco-friendliness, or the economic incentive as eventual goal for performing the practice.

\section{Ridesharing activities}

The data collection reveals 10 ridesharing activities performed by both drivers and passengers: Creating a profile, posting a ride and reserving a seat, coordinating, driving, exchanging monetary compensation, exchanging opinions, relaxing, snacking, saving and earning money, and rating peers. Table 3 describes these activities that constitute the ridesharing practice through a "confessional tale" (cf. Van Maanen, 2011) with examples from the dataset. Ridesharing participants go through most or all of the ridesharing activities in varying manners, contingent to their understandings, procedures, and engagements in the practice. As such, they exhibit different nuances of collaborative consumption based on their grasp of the ridesharing practice. Three collaborative consumption styles are outlined: Communal, consumerist, and opportunistic. Table 4 summarizes the meaning of the ridesharing activities and interactions for each style of collaborative consumption. 
Table 3. Ridesharing activities.

\begin{tabular}{ll}
\hline Activity & Description \\
\hline Creating a & To become a member of the platform, one must create an online \\
profile & profile with personal information (i.e. picture, "mini-bio", online \\
& payment and contact information). Additional information can be \\
& provided to complete a more trustworthy profile, such as \\
& uploading an ID, connecting social media accounts, indicating \\
& ride preferences (i.e. chattiness level, smoking, music, pets), and \\
& accepting the "Member's Agreement" as a statement of good \\
& conduct. Drivers must upload details of the car (i.e. information \\
& used in matching ridesharing participants and for contracts with \\
& insurance partners).
\end{tabular}

Posting a ride As peer providers, drivers post the rides online by providing the (peer providers) necessary information for a successful match with passengers Examples

or reserving a travelling on the same itinerary: Date, detailed itinerary (i.e. point seat (consumers) of origin, destination, time flexibility, possible detours), number of seats available, maximum luggage size, and price. The platform assists drivers by suggesting a fixed price per seat for the ride (and between stopovers), based on estimated fuel consumption and road tolls, but also the car's comfort and maintenance costs. After searching and finding a suitable ride, passengers can decide to reserve a seat through the online registration system, or ad hoc by contacting the driver.

Coordinating The platform facilitates interactions, but the responsibility to coordinate a ride with several consumers mostly depends on the peer providers. The longer the itinerary, the more potential stopovers and passengers, the greater necessary coordination from drivers. Drivers also have to anticipate passengers who are late, cancel, or do not notify anything. Passengers can ask for detours.

\section{Driving The core of ridesharing is the $\mathrm{P} 2 \mathrm{P}$ mobility service from one} location to another by driving a car. The driver is responsible for the passengers safety and comfort.

Exchanging
monetary
compensation

Exchanging opinions

Relaxing
Either online via the reservation system, or in the car with cash. The act of exchanging monetary compensation makes the difference between ridesharing roles more salient: The driver is a service provider, the passenger is a customer.

During the ride, car occupants greet each other and make small talk, and if affinities emerge, they discuss deeper topics. This exchange of opinions can lead to friendships. Chatting about $\mathrm{BlaBlaCar}$ and ridesharing in general enables the community to disseminate knowledge of the practice and to perpetuate itself.

Passengers can take the opportunity to enjoy some personal time during their ride. As they are being driven to their destination, they can relax.
- Experienced members have a richer profile than newcomers.

- Only few passengers had provided a profile picture, or connected their Facebook account.

— Gilles offers his empty seats on his commute twice a week, and he only accepts online reservations in order to filter out travelers who are not committed to sharing the ride and who might cancel last-minute. - For her first ride, Nelia did not understand the online reservation system so she directly contacted the driver to reserve a seat and paid cash during the ride.

- As a driver, Gilles puts efforts in correcting the platform's meet-up times and locations (e.g., traffic). - Magda reserved a seat less than 24 hours prior the ride, and cancelled just before the scheduled departure. - Yuliya changed her mind during the ride about her drop-off location $(25 \mathrm{~km})$.

- Moundir offered to pay double for a detour, and then cancelled.

- Julio, as a passenger, offered to drive during his 8hour ride.

- Marie and Jenna's drivers speeding on the highway.

- As a passenger having paid her ride online, Julie expected her driver to drop her off where she wanted, as part of the service.

- As a driver regularly ridesharing, François thinks his passengers consider him a taxi driver because he receives money from them.

- Amanda loves to hear personal anecdotes.

- More experienced passengers were talkative.

Passengers with limited experience were curious about ridesharing, asking for stories and personal anecdotes.

- Anaïs' driver shares rides to meet new people.

- Julio willingly engaged in discussions and explained that this social aspect of ridesharing was important.

- Yuliya listened to music on her tablet and napped.

- Sofia sat at the back and tried to read her book.

- Omar and his friend watched videos on their phone. 


\begin{tabular}{|c|c|c|}
\hline Activity & Description & Examples \\
\hline Snacking & $\begin{array}{l}\text { Ridesharing participants prepare drinks and food for the journey, } \\
\text { they break along the itinerary for a quick snack or they can share } \\
\text { a meal at arrival. }\end{array}$ & $\begin{array}{l}\text { - Marie prepared snacks for the long journey. } \\
\text { — Drivers are irritated by passengers who eat in their } \\
\text { car without permission. }\end{array}$ \\
\hline $\begin{array}{l}\text { Saving and } \\
\text { earning money }\end{array}$ & $\begin{array}{l}\text { Drivers can increase their cost-savings with ridesharing, and even } \\
\text { get overcompensated and earn money (e.g., by increasing the } \\
\text { number of seats available to fill-up the car completely, or by } \\
\text { offering shuttle services on popular itineraries) such as } \\
\text { independent contractors of ride-hailing companies do. }\end{array}$ & $\begin{array}{l}\text { — Barthélémy makes up to } € 100 \text { a week by driving to } \\
\text { the airport regularly. } \\
\text { - Philip drives } 1500 \mathrm{~km} \text { a day in a nine-seater van, } \\
\text { regrouping various ride offers into one. } \\
\text { — Rueben switched platform to avoid fees. }\end{array}$ \\
\hline Rating peers & $\begin{array}{l}\text { Ridesharing participants give each other a rating from one to } \\
\text { five, as well as a review. The peer ratings are aggregated in a } \\
\text { reputation score displayed on the profile, and all reviews are } \\
\text { public. }\end{array}$ & $\begin{array}{l}\text { - Julie, Nelia, and Yuliya decided to share a ride with } \\
\text { their driver, based on the positive peer reviews. } \\
\text { - In four years, Amanda gave } 42 \text { reviews but only } \\
\text { received } 21 \text { from her peers. }\end{array}$ \\
\hline
\end{tabular}


Table 4. Collaborative consumption styles.

\begin{tabular}{lll}
\hline $\begin{array}{l}\text { Ridesharing } \\
\text { activity }\end{array}$ & Communal style & Consumerist style \\
& $\begin{array}{l}\text { Participants seek pro-social } \\
\text { relationships in belonging to a } \\
\text { community with values of sharing, }\end{array}$ & $\begin{array}{l}\text { Participants seek status and } \\
\text { convenience, following an access } \\
\text { altruism, and generalized }\end{array}$ \\
& reciprocity. & commercial orientation.
\end{tabular}

Creating a profile

Profile completed with personal information and preferences, in honesty and transparency, to foster trustworthy interactions.

\section{Posting a ride and Reserving a seat}

\section{Coordinating}

\section{Exchanging monetary compensation}

Exchanging opinions

\section{Relaxing}

Snacking

\section{Saving and earning money}

Rating peers
The online payment/reservation system is avoided to prefer a more genuine ad hoc organization of the exchange (e.g., via direct contact).

To facilitate the exchange(s), participants collaboratively coordinate and agree on meeting locations and times. Adjustments are made in the spirit of helping one another.

Traffic rules are respected. Driving is safe and courteous. The role of peer provider (driver) can be shared between participants.

Cash compensation is exchanged faceto-face, as agreed online, but this is not enjoyed.

Talking to fellow participants adds social value to collaborative consumption. Strangers can become friends for life after sharing a few personal stories and Facebook contact information.

Collaborative consumption is thought Consumers consider it acceptable to of as an opportunity to bond with other sleep, listen to music, read, etc. while participants, instead of taking time for others are close by. oneself to relax.

Sharing snacks is used to initiate social Water is expected by consumers who interactions.

Collaborative consumption is not necessarily performed to save money, and definitely not to earn money.

Activity conducted as a way to give back to the community (i.e. influencing future exchanges).
Profile with payment information and preferences to facilitate matchmaking, but incomplete without detailed personal information (e.g., no picture, no profile description).

The registration system is used at it makes it easier to manage reservations/cancellations. The platform fee (e.g., insurance and administration costs) guarantees comfortable transactions to participants.

Participants do not put much efforts in helping each other (i.e. unless it is convenient for oneself). Consumers expect professional on-demand services.

Traffic rules are respected.

The compensation is thought of as a payment for due service, but it is hidden (i.e. reservation codes). A tip can be added.

As in a commercial relationship, participants engage in polite small talks but not in personal information. are used to other on-demand shared mobility services (e.g., ride-hailing).

Collaborative consumption is performed in the objective to compensate or reduce one's costs, not to earn money.

Activity conducted to increase one's the more experience, the more status in reviewing past exchanges. the community).
Participants seek to achieve monetary gain or personal benefits from abusive activities, regardless of the authentic sharing culture and original communal norms.

Minimum-required profile (i.e. contact and payment information). Multiple accounts with diverging information (e.g., fake names) can be created to bypass the platform's security (and quality control) measures.

Peer providers and consumers cheat the reservation system to yield monetary gains.

Peer providers do the most in their capacity for the exchange(s) to happen, so that more exchanges are facilitated overall. Conversely, consumers do not concede on their personal goals for the exchange (e.g., time and location).

Rules can be broken (e.g., speeding). The itinerary is chosen according to profitability (e.g., avoid tolls). The role of provider of a mobility service is endorsed with professionalism.

The compensation is assimilated to a traditional commercial transaction between a firm and a customer.

Talking is not likely.

Every opportunity to relax is offered and pursued.

Food and drinks are offered by drivers to get a satisfactory peer review.

The platform's pricing mechanism is very well understood so that it is leveraged to earn money.

Activity likely not undertaken as there are no personal benefits involved in 


\section{Communal collaborative consumption}

The communal style of collaborative consumption is close to the true sharing ethos, altruism, and generalized reciprocity with a pro-social orientation and centered around community values. Historically, ridesharing participants engaged with the ridesharing movement for its socioenvironmental potential, exhibiting a more community-oriented practice than new ridesharing participants nowadays. As such, the communal style is more likely performed by the participants who have had previous experience creating pro-social relationships through collaborative consumption, and who are concerned with belonging to a community (i.e., in particular, the original ridesharing community).

The platform profiles include the participant chattiness from "Bla" (taciturn) to "BlaBlaBla" (very talkative), which indicates the role of exchanging opinions in ridesharing that is particularly salient in the communal style. For instance, since beginning ridesharing in 2011, Amanda became friends with several participants: "Ridesharing is above all a human story, with really different people who tell crazy anecdotes about their experiences and everything. We find ourselves sharing the same ideas, having friends in common ... The world is small!" (online conversation, 2015). As their online profiles suggested, Yuliya and Julio also willingly engaged in discussions in the car and explained that this social aspect of ridesharing was important for them. Anaïs' testimonial further shows how her driver shares rides for the social interactions: "The man was very kind.... At the first stop, he bought us all coffee. At the second, we had a picnic. At the end, he said: "So kids (we were three youngsters), I will not take your codes, I won't make you pay, I just wanted some company...» We all felt embarrassed. It's actually for trips like this that one wants to pay!" (Ouest France, 2015).* The direct reciprocity evoked in Anaiis' statement shows that she expected a commercial transaction (i.e., her role of paying customer) in ridesharing, but it also shows that the driver shares rides for the communal benefits found in conversing and interacting with strangers. Eventually, most online testimonials illustrate newcomers' first experiences as "less awkward than anticipated," thanks to BlaBlaCar's rich FAQ, friends' referrals, and the "warm welcome of the community". The more experienced participants share their acquired knowledge, explaining good and bad practices, their own first rides, and any "rules in my car" (for drivers).

The more community-oriented participants provide additional personal information in their profile, so that other community members perceive each other as friends rather than strangers. Nelia, who was travelling alone with the driver, felt safe and trustful from the information contained in the online profile. That is, newcomers pay particular attention to their peers' reputation by looking at rating history. For instance, Yuliya appeared apprehensive and nervous in her repetitive questions, but after exchanging 38 messages over nine days, she reserved a seat. In the car, she said that it is the testimonials from the BlaBlaCar community that made the driver's profile trustworthy. Julie also chose her ride because of the positive online reputation. Moreover, rating peers after a ride is an activity that benefits only future interactions within the BlaBlaCar community, so it can be considered generalized reciprocity.

In a communal style, participants ideologically associate collaborative consumption with a social exchange opportunity (e.g., keeping company). Sharing snacks as a way to facilitate the creation of social bonds with others is performed collectively instead of relaxing egoistically (cf. opportunistic style). For instance, for her 6-hour ride, Marie had prepared some snacks to pass the time. Some drivers offer to host potluck dinners (writing it in their ride's description), emphasizing the likelihood for social interactions. Ridesharing participants who often travel on the same 
itinerary can also keep each other's contact information to meet thereafter, but also to bypass BlaBlaCar's fees and "share rides like it used to be". Instead of relying completely on the platform functionalities that "dehumanize" the practice, participants in the communal style prefer a more genuine ad hoc organization of ridesharing. During the participant observation, several passengers deliberately avoided the online registration system for this reason, and others added to not trust BlaBlaCar with their financial information.

Even though money is exchanged, communal-style participants understand ridesharing as a pro-social practice fostering feelings of community belonging, rather than as a commercial exchange. They do the most to preserve this sharing ethos from the original ridesharing practice and its grassroots orientation, often by blaming the platform for inciting drivers to raise the price of their ride to make sure they cover more than their travel costs. Maud, usually taking on the driver's role, illustrates the misconception: "I made a trip as a passenger and the driver talked to me, as always, about the principle of ridesharing. I choked when I heard «pay off the vehicle wear, etc.» The driver is the only one who has to pay the wear and tear of the vehicle because with or without the passengers, he makes the trip!! This money is rarely used to clean the seats it seems to me... The passenger should not have to pay the vehicle or pay the driver otherwise it is no longer sharing, it becomes a service and I find this argument inadmissible for a system supposed to be based on courtesy." (parigotmanchot.fr, 2015).* The idiom "we are in it for the long haul" applies to the communal style of collaborative consumption. Even though participants feel indebted in a dyadic exchange (direct reciprocity in a market logic), they also feel part of a bigger community (generalized reciprocity in a social context).

Another characteristic of the communal style is that participants intend to help their fellow community members to the best of their capacity. For instance, as an experienced driver who has shared rides on his commute since 2011, Gilles recognized the required effort in coordinating rides: "One has to be a little organized to ensure the appointments, especially in terms of the times, because the site does not always have a fair estimate of the routes, especially with traffic congestion, for example" (parigotmanchot.fr, 2015).* That is, communal-style peer providers accommodate for stopovers or detours, and communal-style consumers understand the complexities of organizing long-distance ridesharing and they may contribute to the navigation by recommending a better route based on their local knowledge. Eventually, whereas driving is expected to be performed by the person who posts the ride online (i.e., the car owner), the peer provider role (i.e., driver) can be exchanged between car occupants in the communal style.

\section{Consumerist collaborative consumption}

The consumerist style places less emphasis on the social aspect of collaborative consumption, and more on the potential to achieve a more convenient and trendy lifestyle (i.e., access over ownership) by exploiting existing but underutilized assets. For instance, the online registration system is very convenient for drivers who only share rides on their commute and have little room for itinerary adjustments with passengers (e.g., stopovers, detours). Passengers appreciate the ease of use procured by the "instant booking" option (unlike the communal style), which renders the exchange of money almost invisible (ridesharing participants are reminded of their roles when exchanging the reservation code in the car). That is, there is a salient commercial orientation. In the consumerist style, passengers are likely to consider themselves as customers (payers) of a mobility service from professional providers (payees). François is frustrated regarding this commercial orientation and 
professionalization of ridesharing: "I drop my prices compared to my competitors while taking only a maximum of three passengers, offering water, cereal bars, etc. I do the max, I force myself to have a near perfect driving. But this is not enough: If I get stuck in traffic during the trip, passengers hold me responsible for the delay because...they paid" (comptoir.org, 8 November 2015).* François used to share rides as if he were helping out a friend on his itinerary, but he is now stuck in the mechanisms of $\mathrm{P} 2 \mathrm{P}$ markets in the role of mobility service provider. However, his passengers are not interested in who provides them the service.

When opting for the ad hoc cash payment, money is exchanged in the car, which makes the roles more salient. Rueben revealed that when carpooling.com started to collect fees in 2014, he signed up to blablacar.de, which was free. ${ }^{2}$ Ironically, Rueben contributed $€ 5$ for the ride instead of the $€ 4$ previously agreed on. Tipping in ridesharing is an example of direct reciprocity from the passenger to the driver and a symbol of professionalization and market exchange (in contrast to the generalized reciprocity evoked in the communal style). Moreover, ridesharing participants with a consumerist style are less interested in making new friends than in taking the opportunity to relax (e.g., sleep, individualistic activities). If they could afford it, they would travel by train instead of ridesharing (contrary to the communal style where participants collaborate by choice rather than necessity).

Online discussions reveal that some participants use a partner's or friend's profile to post or reserve a ride, which can make other car occupants feel cheated. For example, Alizée protests when she ends up driving next to total strangers (lexpress.fr, 2016). In line with increased convenience and seeking to achieve status, several participants want a more professional rating system, with additional criteria (e.g., cleanliness of the car, kindness, breaks). That is, service quality is poorly reflected in peer ratings. BlaBlaCar encourages passengers to give higher ratings to drivers who make detours, but it is not justified to leave a negative rating if "your ridesharer did not want to make the detour that you had asked them to make", which further indicates a bias. Mostly, drivers complain about the extreme criticism from passengers who punish them for not agreeing to detours (i.e., typical for consumerist collaborative consumption).

The consumerist ideology evoked in this style of collaborative consumption still benefits the ridesharing community as a whole, as participants fuel the supply (peer providers) or demand (consumers) to be matched in the P2P market, but the individual interests and commercial habits contrast with the altruistic and anti-consumption values of the communal style. Participants' selfinterest and utilitarian motives (i.e., convenience, cost-saving, access lifestyle trend orientation) are more important than pro-social interactions. The consumerist style is also adopted by conspicuous participants who engage in collaborative consumption as a way of differentiating themselves from traditional consumption practices and reach a higher status, while expecting the professionalism and commercial relationships offered by traditional B2C offerings. Nevertheless, consumerist collaborative consumption is enacted in a context regulated by platform rules, and in respect of established communal norms, which limits dubious behavior (unlike the opportunistic style).

\section{Opportunistic collaborative consumption}

The opportunistic style is enacted by participants who are willing to forego the communal norms to achieve greater personal benefits: They take advantage of the social aspect of the exchange at the expense of their peers. It is embedded in the market exchange norms of resource exploitation, 
professional service provision, and profit maximization. For instance, some drivers look at and compare other rides to propose an attractive offer and secure a maximum of reserved seats. Francesca's blogpost also emphasizes the role of service provider: "Some tips if you are driver: Post your $a d$ [emphasis added] as soon as possible, do not exaggerate on the price (the competition is tough), drop-off at the train station downtown, although it will make you take a detour but you will be more likely to fill your car" (autour-des-mondes.com, 2015).* On the other side of the P2P market, passengers expect the professional coordination (e.g., home pick-up) of an on-demand mobility service. For instance, Julie, a French student at a business school in Paris worried about delays and that "it was not normal to be late". Eventually, she and her boyfriend decided to sit at the back of the car together (as they would in a taxi) for a three-hour ride before asking to be dropped off at a location that involved a 30-minute detour from the original itinerary. Similarly, Françoise decided to stop driving because she became fed up with passengers treating her commute like a professional mobility service. She could not understand her colleague "who offers rides to a crazy level of service", providing water and snacks to passengers and making long detours regardless of traffic congestion (online conversation, 2015).

The opportunistic style is more likely performed by the more experienced participants, who use knowledge of the ridesharing practice to obtain the greatest benefit for themselves. This is in line with long-time community members who noticed a change of culture, particularly about the perverse effects of the cost-saving incentive of ridesharing framed as opportunity costs: Some drivers want to use all available seats in their car, not only to reduce costs, but to earn money. For instance, Anne-Sophie met a casual driver who incrementally "saves up" €300 per month by making sure his car is full on each of his rides, and making detours through the center of Paris to fill all empty seats, so that he is overcompensated (arretsurimages.net, 2015). Philip goes further by offering three Paris-Lille round-trips $(225 \mathrm{~km})$ in a day: "We started off the thing with two buddies. They do the week, I take the weekends," and he hands out a business card (rue89.fr, 2012).* Several online testimonials reveal that drivers do not always own a driver's license. Furthermore, Jenna recalls her driver explaining the use of GPS devices and speed-trap detectors to be able to drive faster (rue89.fr, 2012). Although BlaBlaCar's terms of services and French law forbid such misbehaviors, these quasi-professionals hijack the platform to find revenues by making ridesharing a business, as stated by another opportunist who provides rides during his work breaks to compete with taxi providers: "These trips are not really ridesharing, I surf the trick. But it's more about helping people to not pay as much for such a short trip [airport-city center]. I'm doing this as a service" (rue89.fr, 2016). "However, passengers are disappointed by such deceptive and abusive behavior because even though the mobility service is provided, there is no social exchange. BlaBlaCar has been trying to weed out such platform members by screening newly created accounts for scams and removing accounts with many negative ratings. However, Aude explains that "illegal taxi drivers implement strategies to bypass the control systems by creating multiple accounts under false names, registering on several sites at once, and they are careful to provide comfortable rides to travelers so they do not report them" (20minutes.fr, 2013).*

Passengers can also cheat, as Marina explains: "Several passengers travel on the same reservation, on a long trip. At the end, they do not communicate the code or a fake code, in order to contest the ride to BlaBlaCar as if you did not transport anybody" (motarde.com, 2013). * Rueben mentioned that he also noticed a change in his fellow passengers' behavior since he started sharing rides: "People can seem nice at first, but then they just want to duck in on the back seat. Before, people used to keep each other company during the drive." For instance, in Hamburg, Sofia wanted 
a back seat to be able to read a book, letting Allan sit at the front and do the talking. Similarly, Yuliya listened to music on headphones and later slept for the last stretch of her trip. Later on, Omar and his friend discreetly laughed at the back, not sharing their jokes with others; then they watched videos for most of the $90 \mathrm{~km}$ ride.

Ridesharing participants misbehaving in such an opportunistic style are the unintended consequences of the exploitation ideology promoted by the platform itself and the sharing economy at large. For instance, a driver can deliberately choose to take an alternative route in order to save road tolls, believing that the community will understand. Michel always asks the driver whether the ride's itinerary is to follow the highway (faster, but more expensive) or the local roads (cheaper, but longer) since drivers had cheated him before (online conversation, 2015). That is, ridesharing activities are performed for opportunistic motives (in contrast to the communal style). For instance, some drivers stock up on water bottles to distribute to their passengers, arguing that they would appreciate it themselves, but also because it might positively influence their peer review of the ride.

In the opportunistic style of collaborative consumption, participants behave as if conducting transactions with a business corporation (such as last-minute cancellations and unadvised noshows), which they would not do to friends or family. That is, participants behave opportunistically against their peers because they are strangers, regardless of the shared online community membership (and BlaBlaCar's efforts in aggregating and governing it). For instance, less than 24 hours before her ride, Magda reserved a seat between Rostock and Hamburg, but then canceled a few hours before the scheduled departure. Collaborative consumption platforms use a reputation system to reduce the perceived risks of sharing with strangers, and peer ratings are used to maintain a high quality of services. Similarly, the opportunistic style of collaborative consumption undermines the trust of a community to yield personal benefits.

\section{Discussion}

Previous research showed that sharing economy platforms vary in their degrees of market mediation, collaborative consumption practices diverge on a sharing-exchange continuum, and practice styles differ on commercialization and socialization dimensions (Davidson et al., 2018; Habibi et al., 2016; Herbert and Collin-Lachaud, 2017). That is, the ridesharing practice depicted in the study is embedded in both market exchange and social norms, from which three styles of collaborative consumption emerged based on the participants' perception of the practice and the activities performed: A communal style, a consumerist style, and an opportunistic style. This is in line with the conceptualization of a market as continuously evolving, where actors extricate economic exchange from the social realm (cf. Araujo et al., 2010), and particularly "concerned markets" where "the economic and the social writ large are intricately entwined" (Geiger et al., 2014, p. 2) such as in the collaborative consumption context. Perren and Kozinets (2018) also argued that P2P markets are embedded with "consociality" and market norms, which can lead to social but commoditized, opportunistic, and ephemeral relationships.

The 10 activities performed by study participants constitute the ridesharing practice: Creating a profile, posting a ride and reserving a seat, coordinating, driving, exchanging monetary compensation, exchanging opinions, relaxing, snacking, saving and earning money, and rating peers. In particular, these activities relate to previous studies of value co-creation using practice theory. For instance, the key activity of coordinating was also found in the 'relating' practices (i.e., 
cooperating, helping, connecting, and tolerating activities) of customers in B2C access-based consumption (Hazée et al., 2017), in 'helping' interaction value practices among employees (Echeverri and Skålén, 2011), and in the value co-creation practice styles in the healthcare sector (McColl-Kennedy et al., 2012). Schau et al. (2009) also found 'welcoming' (i.e., greeting new members, assisting them in brand learning and community socialization) to be a value creation practice among online community members, which is highly emphasized in exchanging opinions. Echeverri and Skålen (2011) also found 'greeting' as interaction value practices, and the core activity of driving is similar to 'delivering' practices. Eventually, Benoit et al. (2017) also proposed 'providing information' and 'personalizing the service' as necessary collaborative consumption activities for consumers and peer providers (respectively), which is similar to creating a profile and posting a ride.

The three collaborative consumption styles differ from previous research on practice styles in the B2C context (Chandler and Chen, 2016; McColl-Kennedy et al., 2012). First, the communal style of collaborative consumption entails participants seeking pro-social relationships in belonging to a community with values of sharing, altruism, and generalized reciprocity. As compensation is involved in collaborative consumption, the communal style is not true sharing (Belk, 2010, 2014a). However, similar to anti-consumption and grassroots practices (e.g., Albinson and Perera, 2012; Gollnhofer et al., 2016; Martin et al., 2015), the communal style is embedded in a sharing ethos. Participants form a large social network, co-creating value (e.g., mobility) with their private assets, and sharing a sense of communal belonging (Benkler, 2004; Fiske, 1992). This also includes giving to the community without expectations, and altruistic concerns (Fiske, 1992; Price, 1975; Sahlins, 1972). In a nutshell, the communal style of collaborative consumption is reflected in Belk's definition of the phenomenon as online-facilitated sharing (2014a). However, this study shows that the original practice of casual ridesharing (Belk, 2014a, 2014b; Benkler and Nissenbaum, 2006) has been influenced over time by digital technologies and shaped into a P2P market by online platforms. Even though some ridesharing participants see their practice in the continuity of secondhand redistribution systems and other non-monetary grassroots initiatives, the communal style of the ridesharing practice is fading in the current sharing economy context where consumers use new on-demand, cost-efficient services. For instance, some might engage in ridesharing because the access lifestyle is trendy, and they have heard about BlaBlaCar through word-of-mouth, but they are not inclined to pro-social relationships - which is the consumerist style of collaborative consumption.

Second, the consumerist style of collaborative consumption entails participants seeking status and convenience, following an access lifestyle trend, and with a commercial orientation. Lifestyle trend orientation and convenience have been found primary drivers of collaborative consumption (Davidson et al., 2018; Hamari et al., 2016; Moeller and Wittkowski, 2010), in line with the access paradigm where B2C customers seek cost-savings, but also status and variety in consumption (Bardhi and Eckhardt, 2012; Lamberton and Rose, 2012; Lawson et al., 2016; Oyedele and Simpson, 2018; Schaefers et al., 2016a). Convenience (e.g., low utility costs) is also one the motives for participating in file-sharing (Hennig-Thurau et al., 2007; Plouffe, 2008), which is a different practice than market exchange, but where the community is used for social distinction (Giesler, 2006). Similarly, Schor et al. (2016) found that participants in timebanks, foodswaps, makerspaces, and open education deploy cultural capital via distinguishing practices (e.g., seeking to achieve high status by acting with professionalism and showing knowledge). Moreover, previous studies have also highlighted this apparent consumerist ideology in collaborative consumption 
(Herbert and Collin-Lachaud, 2017), which simulates overconsumption (Parguel et al., 2017). Yang et al.'s (2017) view on collaborative consumption also promotes the consumerist style. They argue that peer providers can further develop interpersonal relationships with their own customers, and encourage them to customize and professionalize their services (but without special treatments). However, Yang et al.'s (2017) conception of Dida (i.e. Uber's Chinese competitor) as a form of ridesharing is misleading-it is ride-hailing. Anti-consumption practices, even though free of monetary involvement, also aspire to new ways of consuming goods (Albinsson and Perera, 2012). Non-profit grassroots organizations (e.g., Freegle, CouchSurfing) within the sharing economy tend to become more complex and commercially oriented over time (Martin et al., 2015). The consumerist style of collaborative consumption echoes existing customer segmentations, such as 'commercial sharers' with higher monetary motivations and materialism values (Bucher et al., 2016), 'change seekers' who are least materialistic but seeking variety, or the cost-conscious 'fickle floaters' (Lawson et al., 2016).

Third, the opportunistic style of collaborative consumption entails participants seeking to achieve monetary gain or personal benefits from abusive activities, regardless of the authentic sharing culture and original communal norms. This resonates with previous studies that found freeriders in "book-sharing" and "foodsharing" practices who use the communal system to their own benefit without contributing anything in return (Albinsson and Perera, 2012; Corciolani and Dalli, 2014). Similarly, file-sharing practices are driven by opportunistic behavior (Hennig-Thurau et al., 2007) and misbehaviors manifest in the context of access-based consumption (Bardhi and Eckhardt, 2012; Schaefers et al., 2016b). However, such opportunistic and abusive behavior impedes true sharing (Belk and Llamas, 2012), as it lacks the principle of justice (Gollnhofer et al., 2016). The lack of communal identification found in B2C access-based consumption studies (Bardhi and Eckhardt, 2012; Lamberton and Rose, 2012; Schaefers et al., 2016a) also reflects the opportunistic style of collaborative consumption. In a nutshell, the opportunistic style exploits others' generosity, violates the sharing ethos, and disregards the original community formed around the collaborative consumption practice.

These three styles of collaborative consumption differ: The communal style is more prosocial, the consumerist style is more commercial, and the opportunistic style is more exploitative. While the styles can coexist, how activities are performed and what is expected from peers is different from one style to another, leading to potential dissatisfaction with a specific P2P exchange or the platform. For instance, a consumer with a consumerist style expecting a transaction-based relationship (e.g., assimilating ridesharing to a mobility service) is a mismatch for a peer provider with a communal style expecting to stay in contact (e.g., assimilating ridesharing to meeting new friends), but a good match for a peer provider with an opportunistic style (e.g., assimilating ridesharing to work).

\section{Conclusion}

This study has shown that the old practice of hitchhiking can be partly found in the contemporary ridesharing practice. "Hitchhikers 2.0" use online platforms like BlaBlaCar to organize P2P exchanges, offline. As its name and visual identity indicate, BlaBlaCar aims to facilitate a form of social exchange rather than a mobility service. However, ridesharing participants also assimilate the practice to a form of market exchange; that is, no one rides for free. As such, collaborative consumption practices are embedded in the access paradigm, but distinct from true sharing 
practices and $\mathrm{B} 2 \mathrm{C}$ access-based services. Participants integrate various facets of the ideological tensions between a logic of economic exchange with profit maximization, and a logic of social exchange within a community according to three styles of collaborative consumption: Communal, consumerist, and opportunistic.

\section{Theoretical implications}

The contributions of this paper are threefold. First, this conceptualization of collaborative consumption practices as performed according to styles provides an accurate theoretical framework to further investigate and discuss the phenomenon in service research (e.g., Benoit et al., 2017; Hofmann et al., 2017; Oyedele and Simpsons, 2018; Yang et al., 2017). This study also integrates a comprehensive literature review of previous research on true sharing and access-based consumption. That is, the communal style of collaborative consumption is the closest to sharing practices (though it is market-mediated), the consumerist style is the closest to B2C access-based services (though services are exchanged P2P), and the opportunistic style is a symptom of the increasing commercial orientation and adoption of collaborative consumption practices. These styles also enable a better understanding of participants' activities independently of their context (e.g., ridesharing, or accommodation rental). Moreover, the collaborative consumption styles represent three potential moderators in measuring participants behavior.

Second, by exploring " [...] how opportunism is regulated and monitored within and outside the boundaries of the extended self" (Bardhi and Eckhardt, 2012, p. 896), the present paper adds to the limited body of research on misbehavior in service (Harris and Reynolds, 2004; Schaefers et al., 2016b). The opportunistic style of collaborative consumption, strongly embedded in a commercial logic, had not been previously identified in the literature. As such, it shows that opportunism in B2C consumption where it is the firm that is taken advantage of, is directed against other P2P participants in the context of collaborative consumption. This influences further conceptualizations of value co-creation, as well as co-destruction practices (cf. Echeverri and Skålen, 2011) in the sharing economy (e.g., integrating potential negative impacts).

Third, through an in-depth investigation of what collaborative consumption participants actually do, this study offers a closer and better understanding of the actual interactions in P2P exchanges. Service research on collaborative consumption is scarce, in relation to access-based services (e.g., Hazée et al., 2017; Milanova and Mass, 2017; Moeller and Wittkowski, 2010; Schaefers et al., 2016b). The use of netnography and participant observation provides empirical and methodological support to advance service research onto the multi-faceted sharing economy phenomenon. Hence, such phenomenological observations offer a more comprehensive understanding of the various actors and their roles in the black box of collaborative consumption (Benoit et al., 2017; Rudmin, 2016).

\section{Practical implications}

It is important to understand the different styles of performing a collaborative consumption practice, so that platform managers can better facilitate P2P exchanges. The communal style of collaborative consumption benefits online platforms by fostering the emergence and sustainability of a shared community culture between participants. Platform managers can promote this by establishing 
various memberships levels, reinforcing a sense of belonging, organizing events where the community can meet and exchange personal stories, and rewarding members who behave in a friendly and trustworthy manner towards others. In practice, BlaBlaCar organizes local BlaBlaTimes, national BlaBla-Tours, and yearly BlaBla-Days for its community to meet and exchange experiences. These events are popular in large cities and well-received on social media. Hence, it seems that BlaBlaCar manages to successfully engage its community members, as opposed to Zipcar, which fails to engage their customers (i.e., Zipsters) who avoid communal identification (Bardhi and Eckhardt, 2012; Fournier et al., 2013).

Consumerist practices represent a more commercial and professional mindset than a friendly one: Participants seek to get the most out of their P2P exchanges while respecting the sharing community. Such a style promotes the diffusion of collaborative consumption on a short-term basis, but it undermines long-term community-building objectives. To impede the consumerist and opportunistic styles of collaborative consumption, managers should clearly state what is expected and forbidden in the FAQ section of the platform (i.e., working with tax authorities to control illegal activities) to give behavioral indications to network members. Eventually, platform providers should measure the negative impact of a change of business model, as there is a risk of losing the original community (similar to Couchsurfing's incorporation in 2011 that outraged its founding members).

However, the opportunistic style deceives community members who expect social interactions from collaborative consumption, but only meet self-interested participants. This has implications for perceived service quality of service firms operating online platforms. Opportunistic collaborative consumption is not desired as other participants are dissatisfied and begin to distrust each other, as well as the platforms; as a result, they are in favor of more governance from service providers (Hofmann et al., 2017; Yang et al., 2017). Trust is an established driver of collaborative consumption (Möhlmann, 2015; Papaoikonomou and Valor, 2016). Platforms should design appropriate screening procedures for new members and implement virtual reputation systems (de Rivera et al., 2017; Einav et al., 2015). However, current firm practices using peer ratings as a control system (e.g., Uber deactivating peer providers below 4.7/5) inadequately reflect service quality (Kumar et al., 2018). The extensive communication of the potential cost savings of collaborative consumption can also reinforce misbehavior (see Fullerton and Punj, 2004). Inasmuch as "foodsharing" systems accommodate the capitalist ideology of freeriders (Gollnhofer et al., 2016), platform providers must understand the opportunistic collaborative consumption style in order to address it.

\section{Limitations and further research}

This study used an explorative research design to conduct an in-depth investigation of one collaborative consumption practice. Thus, a major limitation is the generalizability of the findings, particularly to other practices (e.g., accommodation rental). Moreover, previous research on collaborative consumption practices showed that they influence each other across contexts, but they are united by a unique style (Herbert and Collin-Lachaud, 2017), so further research based on a confirmatory research design and using quantitative methodologies could measure collaborative consumption styles across diverse practices, platforms, and sectors (e.g., Habibi et al., 2016, Oyedele and Simpson, 2018). Collaborative consumption participants can also shift practice style over time, such as provoked by trigger events (Chandler and Chen, 2016). These transitions, 
triggers, and spill-over effects across the various practices of the sharing economy should be further investigated, particularly in relation to user experience and platform success.

Another potential shortcoming is the predominance of young participants in the study. However, this reflects BlaBlaCar's emphasis on communicating to young people (students represent 28 percent of passengers), and car ownership's being strongly age-specific. Moreover, the majority of sharing economy participants are millennials (e.g., Kumar et al., 2018; Oyedele and Simpsons, 2018). Future studies could investigate the various roles enacted by collaborative consumption participants (i.e., peer providers or consumers), the differences and similarities between roles that influence service satisfaction in the P2P experience, and how the participation likelihood in the communal style can be raised in future exchanges. Another ridesharing study could also focus on collecting data as a passenger to contrast this study's findings from the resulting observations. Eventually, BlaBlaCar is presented as reducing the environmental impact of driving, though this position has been criticized as a form of 'greenwashing' (Schor et al., 2016). Further studies should focus on the environmental impact of collaborative consumption, while considering the diverse participation styles; that is, whether consumers are in fact increasing consumption because it is cheaper to achieve a status (access lifestyle) rather than because it is environmentally friendly.

\section{References}

Akbar, P., Mai, R. and Hoffmann, S. (2016), "When do materialistic consumers join commercial sharing systems", Journal of Business Research, Vol. 69 No. 10, pp. 4215-4224.

Albinsson, P.A. and Perera, B.Y. (2012), "Alternative marketplaces in the 21st century: Building community through sharing events", Journal of Consumer Behavior, Vol. 11 No. 4 Special Issue: Transformative consumer research and social marketing, pp. 303-315.

Araujo, L., Finch, J. and Kjellberg, H. (2010), Reconnecting marketing to markets, Oxford University Press, Oxford, UK.

Bardhi, F. and Eckhardt, G.M. (2012), "Access-based consumption: The case of car sharing”, Journal of Consumer Research, Vol. 39 No. 4, pp. 881-898.

Bardhi, F. and Eckhardt, G.M. (2017), "Liquid consumption", Journal of Consumer Research, Vol. 44 No. 3, pp. 582-597.

Belk, R.W. (2007), "Why not share rather than own?", The Annals of the American Academy of Political and Social Science, Vol. 611 No. 1 Special Volume: The politics of consumption / The consumption of politics, pp. 126-140.

Belk, R.W. (2010), “Sharing”, Journal of Consumer Research, Vol. 36 No. 5, pp. 715-734.

Belk, R.W. (2014a), "Sharing versus pseudo-sharing in web 2.0”, Anthropologist, Vol. 18 No. 1, pp. 7-23.

Belk, R.W. (2014b), "You are what you can access: Sharing and collaborative consumption online", Journal of Business Research, Vol. 67 No. 8, pp. 1595-1600.

Belk, R.W. (2017), "Sharing without caring", Cambridge Journal of Regions, Economy and Society, Vol. 10 No. 2 Special Issue: Sharing economies? Theories, practices and impacts, pp. 249-261.

Belk, R.W. and Llamas, R. (2012), "The nature and effects of sharing in consumer behavior", in 
Mick, D.G., Pettigrew, S., Pechmann, C. and Ozanne, J.L. (Eds.), Transformative consumer research for personal and collective well-being, Routledge, New York, NY, Chapter 30, pp. 625-646.

Benkler, Y. (2004), "Sharing nicely: On shareable goods and the emergence of sharing as a modality of economic production", Yale Law Journal, Vol. 114, pp. 273-358.

Benkler, Y. and Nissenbaum, H. (2006), "Commons-based peer production and virtue", Journal of Political Philosophy, Vol. 14 No. 4, pp. 394-419.

Benoit, S., Baker, T.L., Bolton, R.N., Gruber, T. and Kandampully, J. (2017), “A triadic framework for collaborative consumption (CC): Motives, activities and resources \& capabilities of actors”, Journal of Business Research, Vol. 79 Special Section: Service research, pp. 219-227.

Bucher, E., Fieseler, C. and Lutz, C. (2016), "What's mine is yours (for a nominal fee) - Exploring the spectrum of utilitarian to altruistic motives for Internet-mediated sharing", Computers in Human Behavior, Vol. 62, pp. 316-326.

Butt D'Espous, V., Deniau, K. and Nguyen, A. (2018), Bringing people closer to the places they love and to each other, BlaBlaCar, Onet-le-Chateau, France.

Catulli, M., Lindley, J.K., Reed, N.B., Green, A., Hyseni, H. and Kiri, S. (2013), "What is mine is not yours: Further insight on what access-based consumption says about consumers", in Belk, R.W., Price, L. and Peñaloza, L. (Eds.), Consumer culture theory Vol. 15 (Research in consumer behavior series) - CCT conference 2013, Tucson, AZ, Emerald, Bingley, UK, pp. 185-208.

Chandler, J.D. and Chen, S. (2016), "Practice styles and service systems", Journal of Service Management, Vol. 27 No. 5, pp. 798-830.

Corciolani, M. and Dalli, D. (2014), "Gift-giving, sharing and commodity exchange at Bookcrossing.com: New insights from a qualitative analysis", Management Decision, Vol. 52 No. 4, pp. 755-776.

Davidson, A., Habibi, M.R. and Laroche, M. (2018), "Materialism and the sharing economy: A cross-cultural study of American and Indian consumers", Journal of Business Research, Vol. 82 Special Section: Global consumer culture and the sharing economy across ethnic groups, pp. 364-372.

De Certeau, M. (1984), The practice of everyday life, University of California Press, Berkeley, CA.

de Rivera, J., Gordo, Á., Cassidy, P. and Apesteguía, A. (2017), “A netnographic study of P2P collaborative consumption platforms' user interface and design", Environmental Innovation and Societal Transitions, Vol. 23 Special Issue: Sustainability perspectives on the sharing economy, pp. 11-27.

Dubois, A. and Gadde, L. (2002), "Systematic combining: An abductive approach to case research", Journal of Business Research, Vol. 55 No. 7 Special Issue: Markets as networks, pp. 553-560.

Echeverri, P. and Skalen, P. (2011), "Co-creation and co-destruction: A practice-theory based study of interactive value formation", Marketing Theory, Vol. 11 No. 3 Special Issue: Critical perspectives on co-creation, pp. 351-373.

Eckhardt, G.M. and Bardhi, F. (2016), “The relationship between access practices and economic systems", Journal of the Association for Consumer Research, Vol. 1 No. 2 Special Issue: Consumer ownership and sharing, pp. 210-225.

Einav, L., Farronato, C. and Levin, J. (2016), "Peer-to-peer markets", Annual Review of Economics, 
Vol. 8, pp. 615-635.

Emerson, R.M., Fretz, R.I. and Shaw, L.L. (2011), Writing ethnographic fieldnotes, $2^{\text {nd }}$ ed., University of Chicago Press, Chicago, IL.

Fiske, A.P. (1992), "The four elementary forms of sociality: Framework for a unified theory of social relations", Psychological Review, Vol. 99 No. 4, pp. 689-723.

Fournier, S., Eckhardt, G. and Bardhi, F. (2013), "Learning to play in the new 'Share Economy", Harvard Business Review, Vol. 91 No. 7-8, pp. 125-29.

Fullerton, R.A. and Punj, G. (2004), "Repercussions of promoting an ideology of consumption: Consumer misbehavior", Journal of Business Research, Vol. 57 No. 11 Special Issue: Examining marketing's unintended consequences, pp. 1239-1249.

Geiger, S., Harrison, D., Kjellberg, H. and Mallard, A. (2014), Concerned markets: Economic ordering for multiple values, Edward Elgar, Cheltenham, UK.

Giesler, M. (2006), “Consumer gift systems”, Journal of Consumer Research, Vol. 33 No. 2, pp. 283-290.

Giesler, M., Veresiu, E. and Siebert, A. (2015), "How to design a sharing market (hint: empathy matters)", Huffington Post, available at: https:/www.huffingtonpost.com/markusgiesler/designing-a-sharing-marke_b_6621888.html (accessed 16 November 2017).

Gollnhofer, J.F., Hellwig, K. and Morhart, F. (2016), "Fair is good but what is fair? Negotiations of distributive justice in an emerging non-monetary sharing model", Journal of the Association for Consumer Research, Vol. 1 No. 2 Special Issue: consumer Ownership and sharing, pp. $226-245$.

Gruen, A. (2016), "Design and the creation of meaningful consumption practices in access-based consumption”, Journal of Marketing Management, Vol. 33 No. 3-4 Special Issue: Design, Consumption and Marketing, pp. 226-243.

Habibi, M.R., Kim, A. and Laroche, M. (2016), "From sharing to exchange: An extended framework of dual modes of collaborative nonownership consumption", Journal of the Association for Consumer Research, Vol. 1 No. 2 Special Issue: Consumer ownership and sharing, pp. 277-294.

Hamari, J., Sjöklint, M. and Ukkonen, A. (2016), "The sharing economy: Why people participate in collaborative consumption", Journal of the Association for Information Science and Technology, Vol. 67 No. 9, pp. 2047-2059.

Harris, L. and Reynolds, K. (2004), "Jaycustomer behavior: An exploration of types and motives in the hospitality industry", Journal of Services Marketing, Vol. 18 No. 5, pp. 339-357.

Hazée, S., Delcourt, C. and Van Vaerenbergh, Y. (2017), "Burdens of access", Journal of Service Research, Vol. 20 No. 4, pp. 441-456.

Hennig-Thurau, T., Henning, V. and Sattler, H. (2007), "Consumer file sharing of motion pictures", Journal of Marketing, Vol. 71 No. 4, pp. 1-18.

Herbert, M. and Collin-Lachaud, I. (2017), "Collaborative practices and consumerist habitus: An analysis of the transformative mechanisms of collaborative consumption", Recherche et Applications en Marketing (English Edition), Vol. 32 No. 1, pp. 40-60.

Hofmann, E., Hartl, B. and Penz, E. (2017), "Power versus trust - what matters more in collaborative consumption?”, Journal of Services Marketing, Vol. 31 No. 6, pp. 589-603. 
Huber, A. (2017), "Theorising the dynamics of collaborative consumption practices: A comparison of peer-to-peer accommodation and cohousing", Environmental Innovation and Societal Transitions, Vol. 23 Special Issue: Sustainability perspectives on the sharing economy, pp. 5369.

Johnson, M., Herrmann, A. and Huber, F. (1998), "Growth through product-sharing services", Journal of Service Research, Vol. 2 No. 1, pp. 167-177.

Kozinets, R. V. (2015), Netnography: Redefined, SAGE, Thousand Oaks, CA.

Kumar, V., Lahiri, A. and Dogan, O.B. (2018), "A strategic framework for a profitable business model in the sharing economy”, Industrial Marketing Management, Vol. 69, pp. 147-160.

Lamberton, C.P. and Rose, R.L. (2012), "When is ours better than mine? A framework for understanding and sharing systems”, Journal of Marketing, Vol. 76 No. 4, pp. 109-125.

Lawson, S.J., Gleim, M.R., Perren, R. and Hwang, J. (2016), "Freedom from ownership: An exploration of access-based consumption", Journal of Business Research, Vol. 69 No. 8, pp. 2615-2623.

LeCompte, M.D. and Schensul, J.J. (2012), Analysis and interpretation of ethnographic data: A mixed methods approach, Ethnographer's toolkit Vol. 5, $2^{\text {nd }}$ ed., AltaMira Press, Lanham, MD.

Lovelock, C. and Gummesson, E. (2004), "Whither services marketing? In search of a new paradigm and fresh perspectives", Journal of Service Research, Vol. 7 No. 1, pp. 20-41.

Martin, C.J., Upham, P. and Budd, L. (2015), "Commercial orientation in grassroots social innovation: Insights from the sharing economy”, Ecological Economics, Vol. 118, pp. 240 251.

McArthur, E. (2015), "Many-to-many exchange without money: Why people share their resources", Consumption Markets \& Culture, Vol. 18 No. 3, pp. 239-256.

McColl-Kennedy, J.R., Vargo, S.L., Dagger, T.S., Sweeney, J.C. and van Kasteren, Y. (2012), "Health care customer value cocreation practice styles", Journal of Service Research, Vol. 15 No. 4, pp. 370-389.

Milanova, V. and Maas, P. (2017), "Sharing intangibles: Uncovering individual motives for engagement in a sharing service setting", Journal of Business Research, Vol. 75, pp. 159-171.

Moeller, S. and Wittkowski, K. (2010), "The burdens of ownership: reasons for preferring renting", Managing Service Quality, Vol. 20 No. 2 Special Issue: Selected papers from the QUIS-11 symposium, pp. 176-191.

Möhlmann, M. (2015), "Collaborative consumption: determinants of satisfaction and the likelihood of using a sharing economy option again”, Journal of Consumer Behavior, Vol. 14 No. 3, pp. 193-207.

Münzel, K., Boon, W., Frenken, K. and Vaskelainen, T. (2017), "Carsharing business models in Germany: Characteristics, success and future prospects”, Information Systems and E-Business Management, Special Issue: Sharing economy and on-demand service business models (online 20 June 20107), doi.org/10.1007/s10257-017-0355-x

Muzellec, L., Ronteau, S. and Lambkin, M. (2015), “Two-sided Internet platforms: A business model lifecycle perspective”, Industrial Marketing Management, Vol. 45, pp. 139-150.

Oyedele, A. and Simpson, P. (2017), "Emerging adulthood, sharing utilities and intention to use sharing services", Journal of Services Marketing, Vol. 32 No. 2, pp. 161-174. 
Ozanne, L.K. and Ballantine, P.W. (2010), "Sharing as a form of anti-consumption? An examination of toy library users", Journal of Consumer Behavior, Vol. 9 No. 6 Special Issue: Sustainability through anti-Consumption, pp. 485-498.

Papaoikanomou, E. and Valor, C. (2016), "Exploring commitment in peer-to-peer exchanges: the case of timebanks", Journal of Marketing Management, Vol. 32 No. 13/14, pp. 1333-1358.

Parguel, B., Lunardo, R. and Benoit-Moreau, F. (2017), "Sustainability of the sharing economy in question: When second-hand peer-to-peer platforms stimulate indulgent consumption", Technological Forecasting and Social Change, Vol. 125 Special Section: Promises and paradoxes of the sharing economy, pp. 48-57.

Perren, R. and Kozinets, R. V. (2018), "Lateral exchange markets: How social platforms operate in a networked economy", Journal of Marketing, Vol. 82 No. 1, pp. 20-36.

Philip, H.E., Ozanne, L.K. and Ballantine, P.W. (2015), "Examining temporary disposition and acquisition in peer-to-peer renting", Journal of Marketing Management, Vol. 31 No. 11-12, pp. 1310-1332.

Plouffe, C.R. (2008), “Examining 'peer-to-peer' (P2P) systems as consumer-to-consumer (C2C) exchange", European Journal of Marketing, Vol. 42 No. 11/12, pp. 1179-1202.

Price, J.A. (1975), "Sharing: The integration of intimate economies", Anthropologica, Vol. 17 No. 1, pp. 3-27.

Reckwitz, A. (2002), "Toward a theory of social practices: A development in culturalist theorizing", European Journal of Social Theory, Vol. 5 No. 2, pp. 243-263.

Ritchie, J. and Spencer, L. (2002), "Qualitative data analysis for applied policy research", in Huberman, A.M. and Miles, M.B. (Eds.), The qualitative researcher's companion, SAGE, London, UK, pp. 305-329.

Rochet, J. and Tirole, J. (2006), “Two-sided markets: A progress report”, RAND Journal of Economics, Vol. 37 No. 3, pp. 645-667.

Rudmin, F. (2016), "The consumer science of sharing: A discussant's observations", Journal of the Association for Consumer Research, Vol. 1 No. 2 Special Issue: Consumer ownership and sharing, pp. 198-209.

Sahlins, M.D. (1972), Stone age economics, Aldine Atherton, Chicago, IL.

Scaraboto, D. (2015), "Selling, sharing, and everything in between: The hybrid economies of collaborative networks", Journal of Consumer Research, Vol. 42 No. 1, pp. 152-176.

Schaefers, T., Lawson, S.J. and Kukar-Kinney, M. (2016a), "How the burdens of ownership promote consumer usage of access-based services", Marketing Letters, Vol. 27 No. 3, pp. 569577.

Schaefers, T., Wittkowski, K., Benoit Moeller, S. and Ferraro, R. (2016b), "Contagious effects of customer misbehavior in access-based services”, Journal of Service Research, Vol. 19 No. 1, pp. 3-21.

Schatzki, T.R. (1996), Social practices: A Wittgensteinian approach to human activity and the social, Cambridge University Press, Cambridge, UK.

Schau, H.J., Muñiz, A.M. and Arnould, E.J. (2009), "How brand community practices create value", Journal of Marketing, Vol. 73 No. 5, pp. 30-51.

Scholz, T. and Schneider, N. (2016), Ours to hack and to own: The rise of platform cooperativism, 
a new vision for the future of work and a fairer Internet, OR Books, New York, NY.

Schor, J.B., Fitzmaurice, C., Carfagna, L.B., Attwood-Charles, W. and Dubois Poteat, E. (2016), "Paradoxes of openness and distinction in the sharing economy", Poetics, Vol. 54, pp. 66-81.

Shove, E. and Pantzar, M. (2005), "Consumers, producers and practices. Understanding the invention and reinvention of Nordic walking.", Journal of Consumer Culture, Vol. 5 No. 1, pp. 43-64.

Spradley, J.P. (1979), The ethnographic interview, Harcourt, New York, NY.

Stabrowski, F. (2017), “People as businesses': Airbnb and urban micro-entrepreneurialism in New York City”, Cambridge Journal of Regions, Economy and Society, Vol. 10 No. 2 Special Issue: Sharing economies? Theories, practices and impacts, pp. 327-347.

SUMC. (2015), Shared-use mobility reference guide, Shared-Use Mobility Center (SUMC), San Francisco, CA.

Van Maanen, J. (2011), Tales of the field: On writing ethnography, $2^{\text {nd }}$ ed., University of Chicago Press, Chicago, IL.

Warde, A. (2005), "Consumption and theories of practice", Journal of Consumer Culture, Vol. 5 No. 2, pp. 131-153.

Wilhelms, M.-P., Henkel, S. and Falk, T. (2017), "To earn is not enough: A means-end analysis to uncover peer-providers' participation motives in peer-to-peer carsharing”, Technological Forecasting and Social Change, Vol. 125 Special Section: Promises and paradoxes of the sharing economy, pp. 38-47.

Wittkowski, K., Moeller, S. and Wirtz, J. (2013), "Firms' intentions to use nonownership services", Journal of Service Research, Vol. 16 No. 2, pp. 171-185.

Yang, S., Song, Y., Chen, S. and Xia, X. (2017), "Why are customers loyal in sharing-economy services? A relational benefits perspective”, Journal of Services Marketing, Vol. 31 No. 1 Special Issue: Relationship marketing - past, present and future, pp. 227-241.

Zervas, G., Proserpio, D. and Byers, J.W. (2017), "The rise of the sharing economy: Estimating the impact of Airbnb on the hotel industry", Journal of Marketing Research, Vol. 54 No. 5, pp. $687-705$. 
${ }^{1}$ As of 2018, BlaBlaCar operates in 22 countries for a total of 60 million registered members. The online registration system (enabling BlaBlaCar to charge a commission) must be opted-in by the driver before passengers can "instant-book" the ride, and it is not available in all countries (depending on BlaBlaCar's local market strategy and regulations).

2 BlaBlaCar acquired its competitor carpooling.com (previously known as Mitfahrgelegenheit) in April 2015 and began charging a platform fee in September 2016 (i.e. after data collection).

* Author's translation.

The author is thankful for the three anonymous reviewers' insightful suggestions and the guiding discussions, as well as the associate editor's comments. The author would like to thank Professor Charles Hofacker, Mario Kienzler, Carolin Schütze, Aku Valtakoski, and Professor Lars Witell for their helpful comments on previous versions of the manuscript.

Hugo Guyader is a Doctoral Candidate in Business Administration at Linköping University. His research interests revolve around collaborative consumption, service marketing, and sustainable consumer behavior. Hugo Guyader can be contacted at: hugo.guyader@liu.se 


\begin{tabular}{|c|c|c|c|}
\hline \multirow[b]{2}{*}{ Amount of data } & \multirow[b]{2}{*}{ Description } & \multicolumn{2}{|c|}{ Perspective } \\
\hline & & $\begin{array}{l}\text { Online } \\
\text { platform } \\
\text { provider }\end{array}$ & $\begin{array}{l}\text { Ridesharing } \\
\text { participants }\end{array}$ \\
\hline $\begin{array}{l}81 \text { opinion articles } \\
\text { and blogposts }\end{array}$ & $\begin{array}{l}\text { BlaBlaCar story: Successes and failures (critiques), mostly } \\
\text { covered by the French press and opinion articles on blogs. }\end{array}$ & $x$ & $x$ \\
\hline $\begin{array}{l}349 \text { testimonials } \\
\text { and } 59 \text { portraits }\end{array}$ & $\begin{array}{l}\text { Selected by BlaBlaCar community managers; profiles of drivers } \\
\text { and passengers are described to encourage platform adoption. }\end{array}$ & $x$ & $x$ \\
\hline $\begin{array}{l}25 \text { online } \\
\text { conversations }\end{array}$ & $\begin{array}{l}\text { Informal interviews with ridesharing participants based on } \\
\text { questions eliciting their best and worst ridesharing experience. }\end{array}$ & & $x$ \\
\hline $\begin{array}{l}\text { Community } \\
\text { comments }\end{array}$ & $\begin{array}{l}\text { Online reactions to articles, Facebook posts, Twitter, blogs and } \\
\text { forums. }\end{array}$ & & $x$ \\
\hline $\begin{array}{l}22 \text { keynotes } \\
\text { and presentations }\end{array}$ & $\begin{array}{l}\text { BlaBlaCar's market strategy and back-end processes, explained to } \\
\text { investors, workshop participants, or conference attendees. }\end{array}$ & $x$ & \\
\hline 282 videos & $\begin{array}{l}\text { BlaBlaCar's YouTube and Vimeo channels listing commercials, } \\
\text { interviews, and reportages, etc. }\end{array}$ & $x$ & \\
\hline $\begin{array}{l}\text { BlaBlaCar FAQ } \\
\text { and documentation }\end{array}$ & $\begin{array}{l}\text { Answers to common questions about ridesharing in general, as } \\
\text { well as rules and guidelines when using BlaBlaCar's platform. }\end{array}$ & $x$ & \\
\hline
\end{tabular}

\section{Appendix B. Participant observation in five ridesharing rides.}

TRIP 1 (16 May 2015)

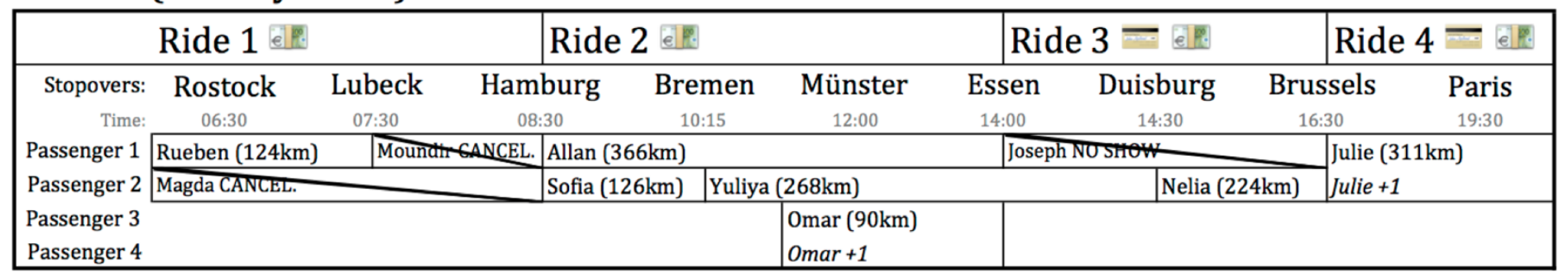

TRIP 2 (25 May 2015)

\begin{tabular}{|c|c|c|c|c|}
\hline \multicolumn{5}{|c|}{ Ride $5=$} \\
\hline Stopovers: & Paris & Düsseldorf & Ferry & Lund \\
\hline Time & $17: 00$ & $22: 30$ & $<7 h>$ & $15: 00$ \\
\hline Passenger 1 & rie (508 & \begin{tabular}{l|l} 
Julio 6 \\
\end{tabular} & & \\
\hline
\end{tabular}

BlaBlaCar limits the number of stopovers to six and determines an approximate departure time for each passenger throughout the itinerary. Therefore, the study comprises five distinct rides, enabling more flexibility with itinerary (until 2018).

The rides were priced in accordance with BlaBlaCar's suggestion and could be reserved ad hoc by internal message and paid for in cash (Rides 1-4), or reserved and paid online with a "Manual Approval - guaranteed within 3 h", (Rides 3-5). At the time of study, the online registration system was only available for rides in France and longer than $75 \mathrm{~km}$ (except for European cities close to French borders). Huber (2017) reported that ridesharing is a widely adopted practice in France (19-25 percent of the population) and in Germany (11 percent).

The online communication with 35 BlaBlaCar members prior to the rides totals 33 pages of text. 